\title{
KOMUNIKASI PEMASARAN TERPADU UMROH ESQ TOUR TRAVEL PT. FAJRUL IKHSAN WISATA
}

\author{
Ela Hulasoh*) \\ el hulaso@yahoo.com
}

\begin{abstract}
ABSTRAK
Penelitian ini bertujuan untuk mengetahui, mengeksplorasi dan menggambarkan tentang penerapan dan pengintegrasian aktivitas komunikasi pemasaran terpadu pada produk umroh ESQ Tours Travel yang merupakan brand dari PT. Fajrul Ikhsan Wisata. Menggunakan teori-teori yang relevan dengan tema riset, yaitu teori komunikasi bisnis, komunikasi pemasaran, dan teori komunikasi pemasaran terpadu. Penelitian ini menggunakan pendekatan kualitatif dengan metode deskriptif dan paradigma fenomenologi. Berlokasi di kantor pusat ESQ Tours travel, Jakarta Selatan. Pengambilan data menggunakan teknik wawancara, observasi serta dokumentasi. dan sumber data dikategorikan menjadi dua, 3 orang staff marketing dan 1 orang staff bagian advertising dan promosi perusahaan sebagai sumber data primer, dan dilengkapi dari sumber data sekunder berupa dokumentasi wawancara, foto, majalah, flier, iklan, dan brosur, dan lain-lain. Data tersebut dianalisa menggunakan model interaktif, diuji keabsahan datanya melalui triangulasi sumber sehingga diperoleh derajat kepercayaan suatu informasi dan data. Hasil dari penelitian ini menjelaskan bahwa ESQ Tours Travel terhadap produk umrohnya telah menggunakan dan mengintegrasikan bauran komunikasi pemasaran terpadunya baik secara personal, kelompok dan massal, berdasarkan model 3 yang dikemukan dalam teori George dan Michael Belch. Dari hasil analisis data dapat disimpulkan bahwa eksistensi dan brand equity yang diraih oleh produk umroh ESQ tours karena faktor keberhasilan dalam melakukan pengintegrasian bauran komunikasi pemasarannya terhadap produk di atas. Dari hasil analisis, disarankan bahwa manajemen ESQ Tours Travel berani beriklan di media massa elektronik, menjadi sponsor berbagai acara religi, dan memiliki staff khusus kehumasan/PR agar lebih terorganisir dan efektif dalam kegiatannya.
\end{abstract}

Kata kunci: komunikasi pemasaran terpadu, marketing, umroh, dan tours travel

\begin{abstract}
ABSTRACK
This study aims to know, explore and describe the application and integration of integrated marketing communications activities on products umroh ESQ Tours Travel which is a brand of PT. Fajrul Ikhsan Wisata. Using theories that are relevant to the theme of research, namely the theory of business communication, marketing communications, and the theory of integrated marketing communications. This research uses qualitative approach with descriptive method and phenomenology paradigm. Located at ESQ Tours travel headquarters, South Jakarta. Data collection using interview technique, observation and documentation. And data sources are categorized into two, 3 marketing staff and 1 staff member of advertising and promotion company as primary data source, and equipped from secondary data source in the form of documentation of interview, photo, magazine, flier, advertisement, and brochure, etc. . The data is analyzed using interactive model, tested the validity of data through triangulation of source so that obtained degree of trust of information and data. The result of this study explains that ESQ Tours Travel on its umroh products has been using and integrating mixed marketing communication mix both personal, group and bulk based on model 3 found in George and Michael Belch theory, although not maximal in its application, And public relations.it is recommended that ESQ Tours Travel mangement dare to advertise in electronic mass media, sponsor various religious events, and have special public relations staff to be more organized and effective in their activities.
\end{abstract}

Keywords : Integrated Marketing Communication, marketing, umra, and tours travel. 


\section{A. Pendahuluan.}

Tours Travel haji dan umroh, adalah salah satu bidang usaha bisnis yang sedang diminati para pelaku usaha dan investor di Indonesia, menjamur di manamana bahkan sebagaimana tercantum di Kementrian Agama ada lebih dari 240 perusahaan penyelenggaraan haji dan umroh. Membidik usaha di bidang tours travel haji umroh bukanlah tanpa alasan yang tidak masuk akal, karena Indonesia adalah Negara dengan kuantitas muslim terbesar di dunia, dengan animo dan antusiasme yang sangat besar dalam setiap bulan juga tahunnya menjalankan perjalanan ibadah rohani berupa haji dan umroh ke Baitullah sebagai bentuk perintah Allah SWT, wisata rohani penuh manfaat, dan menyempurnakan rukun islam.

Peluang besar ini bukan berarti tanpa resiko dan tanpa tantangan yang kecil jika dilihat dari jumlah kompetitor yang ada. Agar dapat bertahan di tengah persaingan itu, maka mereka harus mempunyai strategi komunikasi pemasaran yang tepat. Hal tersebut karena komunikasi pemasaran memegang peranan yang sangat penting bagi produk yang ditawarkan perusahaan tours travel. Tanpa komunikasi pemasaran yang efeketif, konsumen maupun masyarakat secara keseluruhan tidak akan mengetahui keberadaan produk mereka di pasar. Tidak sebatas itu, komunikasi pemasaran ini merupakan sarana yang digunakan perusahaan-perusahaan dalam upaya untuk menginformasikan, membujuk, dan mengingatkan konsumen secara langsung atau tidak langsung tentang produk dan merek yang mereka jual.

Di tengah persaingan dan berbagai hambatan yang harus dihadapi oleh produsen jasa tours travel haji umroh dalam membangun komunikasi pemasarannya, ada yang berhasil sesuai tujuan perusahaan, tapi tidak sedikit yang gagal dalam meraih pasar besar.

Berdasarkan penjelasan tersebut, penelitian ini mengungkapkan bagaimana komunikasi pemasaran terpadu ESQ Tours Travel dalam memasarkan produk jasa umrohnya dan mampu bersaing dengan perusahaan asing yang akan ikut bermain di dalam bisnis jasa di Indonesia dan bagaimana perusahaan siap menghadapi pesaing-pesaing asing di Indonesia dalam persaingan ketat antar perusahaan di kancah MEA. Karena itu penelitian ini akan diuraikan dan dirangkum dengan judul "Komunikasi Pemasaran Terpadu umroh ESQ Tours Travel (Sebuah Studi di PT. Fajrul Ikhsan Wisata)".

\section{B. Perumusan Masalah}

Berdasarkan pemaparan dalam latar belakang masalah di atas, maka yang menjadi fokus permasalahan adalah, "Bagaimana gambaran mengenai bauran komunikasi pemasaran terpadu ESQ Tours Travel terhadap produk layanan umrohnya?".

\section{Tujuan Penelitian}

Berdasarkan rumusan permasalahannya maka tujuan dari penelitian ini adalah untuk mengetahui bagaimana bauran komunikasi pemasaran terpadu produk umroh ESQ Tours Travel 


\section{Landasan Teori}

\section{Pengertian Komunikasi Bisnis}

Bernard Berelson dan Garry A. Stainer, dalam Effendi (2002: 48), mendefinisikan komunikasi sebagai berikut:"communication: the transmission of information, ideas, emotions, skills, etc, by the use symbols-words, pictures, figures, graphs, etc. it is the act or process of transmission that is usually called communication". (komunikasi: penyampaian informasi, gagasan, emosi, keterampilan, dan sebagainya dengan menggunakan lambang-lambang, katakata, gambar, bilangan, grafik dan lain-lain. Kegiatan atau proses penyampaianlah yang biasanya dinamakan komunikasi).

Djoko Purwanto dalam bukunya Komunikasi Bisnis mendefinisikan komunikasi bisnis yaitu "komunikasi yang digunakan dalam dunia bisnis yang mencakup berbagai macam bentuk komunikasi, baik komunikasi verbal maupun komunikasi nonverbal untuk mencapai tujuan tertentu (Purwanto, 2011: 5)".

Komunikasi bisnis yang efektif memiliki dua tujuan utama, yaitu:

1. Mendapatkan pemahaman penuh tentang makna pesan yang diberikan kepada pihak lain, baik di dalam maupun di luar organisasi perusahaan

2. Mendapatkan tanggapan, tindakan atau persetujuan dari si penerima pesan seperti yang diharapkan si pemberi pesan. (Sutojo dan Setiawan, 2003: 1-2).

\section{Pengertian Komunikasi Pemasaran}

Penggabungan dari dua kajian: pemasaran dan komunikasi menghasilkan kajian "baru" yang diberi nama komunikasi pemasaran (marketing communication). Komunikasi pemasaran merupakan aplikasi komunikasi yang ditujukan untuk membantu kegiatan pemasaran sebuah perusahaan. Komunikasi pemasaran adalah kegiatan pemasaran dengan menggunakan teknik-teknik komunikasi yang ditujukan untuk memberikan infromasi kepada orang banyak dengan harapan agar tujuan perusahan tercapai, yaitu terjadinya peningkatan pendapatan (laba) sebagai hasil penambahan penggunaan jasa atau pembelian produk yang ditawarkan. Komunikasi pemasaran merupakan bentuk komunikasi yang ditujukan untuk memperkuat strategi pemasaran, guna meraih segmentasi yang lebih luas. Kajian ini dapat dikatakan juga sebagai upaya untuk memperkuat loyalitas pelanggan terhadap produk yaitu barang dan jasa yang dimiliki perusahaan (Soemanagara, 2012: 3-4).

Komunikasi pemasaran juga dapat dinyatakan sebagai kegiatan komunikasi yang ditujukan untuk menyampaikan pesan kepada konsumen dan pelanggan dengan menggunakan sejumlah media dan berbagai saluran yang dapat dipergunakan dengan harapan terjadinya tiga tahapan perubahan, yaitu: perubahan pengetahuan, perubahan sikap, dan perubahan tindakan yang dikehendaki. Adapun jenis media yang dapat digunakan seperti: folder, poster, banner, fliers, televisi, radio, majalah dan surat kabar (Soemanagara, 2012: 4). 


\subsection{Analisis SWOT Sebagai Dasar dalam Melakukan Kegiatan Pemasaran}

Analisis SWOT menurut Rangkuti (2004: 18-19) adalah identifikasi berbagai faktor secara sistematis untuk merumuskan strategi perusahaan. Analisis ini didasarkan pada logika yang dapat memaksimalkan kekuatan (strength) dan peluang (opportunities), namun secara bersamaan dapat meminimalkan kelemahan (weaknesses) dan ancaman (threats).

Gambar 1 Analisis SWOT

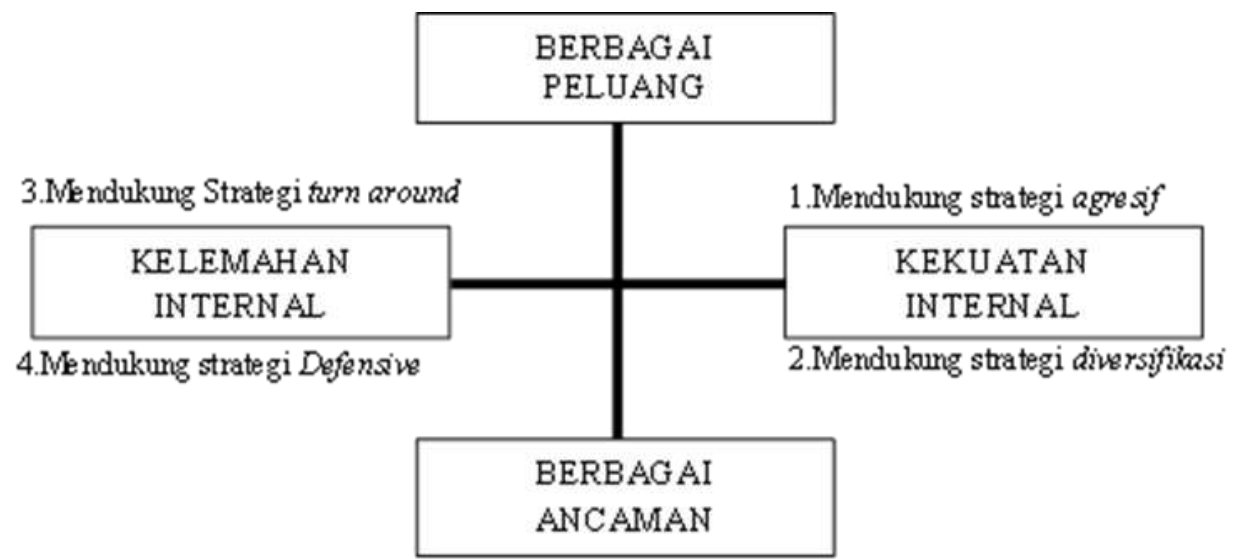

Kinerja perusahaan dapat ditentukan oleh kombinasi faktor internal dan eksternal. Kedua faktor tersebut harus dipertimbangkan dalam analisis SWOT. SWOT adalah singkatan dari lingkungan internal Strengths dan Weakness serta lingkungan Opportunities dan Threats yang dihadapi dunia bisnis (Rangkuti, 2004:18-19). Dengan penjabaran sebagai berikut:

a. Strength, identifikasi atas sumber daya, keahlian atau kelebihan-kelebihan lain yang harus dimiliki perusahaan dalam menghadapi para pesaing.

b. Weaknesses, keterbatasan atau ketidakefisienan sumber daya, keahlian dan kemampuan-kemampuan yang mengakibatkan ketidakefektifan sebuah perusahaan.

c. Opportunities, suatu bidang atau hal dimana suatu perusahaan memiliki keunggulan bersaing yang diperoleh dari kegiatan pemasarannya.

d. Threats, tantangan atau ancaman yang berasal dari lingkungan yang dapat menghambat kegiatan pemasaran atau bahkan mengancam keberadaan suatu perusahaan.

\section{Pengertian Komunikasi Pemasaran Terpadu / Integrated Marketing Communication (IMC)}

Menurut four As (the American Association of Advertising Agency), IMC adalah: konsep perencanaan komunikasi pemasaran yang mengakui nilai tambah dari perencanaan komprehensif yang mengkaji peran strategis masingmasing bentuk komunikasi-misalnya iklan, respon langsung, promosi penjualan dan humas (hubungan masyarakat), serta memadukannya untuk meraih 
kejelasan pesan, konsistensi, dan dampak komunikasi maksimal melalui keterintegrasian pesan.

The Northwestern University's Medill School of journalism mendefinisikan Komunikasi Pemasaran Terpadu sebagai: proses mengelola semua sumbersumber informasi menyangkut informasi produk/pelayanan di mana seorang pelanggan yang memiliki proses didorong sedemikian rupa agar perilakunya tergerak untuk mewujudkan penjualan dan membentuk loyalitas konsumen.

Secara singkat komunikasi pemasaran terpadu (IMC) adalah menyatukan perencanaan, tindakan dan koordinasi pada semua wilayah komunikasi pemasaran dan juga memahami konsumen (Soefijnto, 2012: 52).

Model Komunikasi pemasaran Terpadu menurut George dan Michael Belch, sebagaimana dikutip Morissan, 2010: 17-30, bahwa komunikasi pemasaran terpadu merupakan sinergis antara aktivitas-aktivitas komunikasi pemasaran, sebagaimana digambarkan berikut:

Gambar 2, model komunikasi pemasaran terpadu menurut George dan Belch

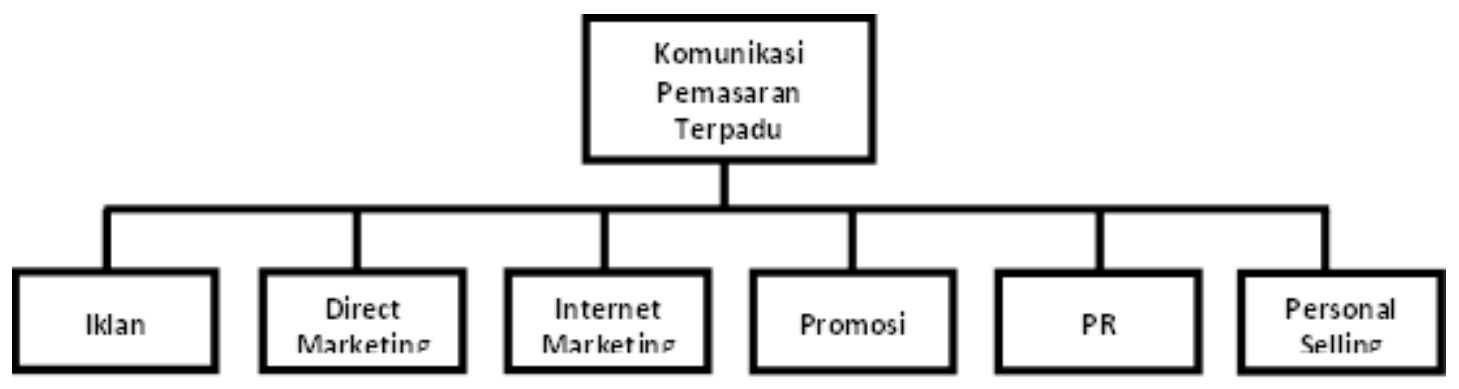

\section{E. Metodologi}

Pendekatan yang digunakan dalam penelitian ini adalah pendekatan kualitatif, yaitu diharapkan dari pendekatan ini mampu menghasilkan suatu uraian mendalam tentang ucapan, tulisan, tingkah laku yang dapat diamati dari suatu individu, kelompok, masyarakat, organisasi tertentu dalam suatu kontek setting tertentu yang dikaji dari sudut pandang yang utuh, komprehensif dan holistic (Bogdan and Tylor, dalam Ruslan, 2003: 203).

Metode yang digunakan penulis dalam penelitian ini adalah deskriptif kualitatif dengan menggunakan paradigma fenomenologi. Mohammad Nazir Tujuan dari penelitian deskriptif ini adalah untuk membuat deskripsi, gambaran atau lukisan secara sistematis, faktual dan akurat mengenai fakta-fakta sifat-sifat serta hubungan antar fenomena yang diselidiki (Nazir, 1988: 63). Sedangkan deskriptif menurut Whitney sebagaimana dikutip oleh Nazir (1988: 63), adalah pencarian fakta dengan interpretasi yang tepat.

Lokasi penelitian yang dilaksanakan adalah di ESQ Tours Travel, yang berkantor pusat di Jl. Ciputat Raya no 1B, Pondok Pinang, Kebayoran Lama, Jakarta Selatan.Sebagaimana yang penulis sampaikan di tinjauan kepustakaan dan kerangka konsep, peneliti akan fokus pada ESQ Tours Travel dalam menjalankan komunikasi pemasaran terpadu terhadap produk umrohnya. 
Dalam penelitian ini ada dua yang menjadi sumber data. Pertama, sumber data primer, yaitu personil pegawai ESQ Tours Travel bagian marketing yang terdiri dari tiga orang pegawai dan 1 pegawai bagian advertising dan promosi. Ke empat informan yang diambil dengan pertimbangan posisi dan pengalaman dan dalam perusahaan tersebut. Dan didukung oleh sumber data sekunder yang berupa hasil dokumentasi wawancara, dokumentasi foto, dokumentasi film, dokumentasi data (grafik, table, majalah, website, brosur, iklan, company profile, dan lain-lain).

\section{F. Hasil dan Pembahasan}

\section{Gambaran Umum Objek Penelitian}

ESQ Tours \&Travel adalah salah satu unit bisnis ESQ 165 (ESQ Leadership Center) yang bergerak dalam bidang jasa pelayanan Tours \& Travel serta Umrah \& Haji dengan CEO Dr. Ary Ginanjar Agustian. Dengan konsep "one stop solution" melalui pelayanan personal touch, e-booking, call center dan pelayanan 24 jam, ESQ Tours \& Travel kini mempunyai 15 kantor cabang yang berlokasi di Sumatera (Palembang, Padang, Pekanbaru, Medan), Jawa Barat (Bandung), Jawa Tengah (Semarang), Jawa Timur (Surabaya), Bali (Denpasar), Kalimantan (Balikpapan) dan Sulawesi (Makassar).

\section{Gambar 2, Logo ESQ Tours Travel}

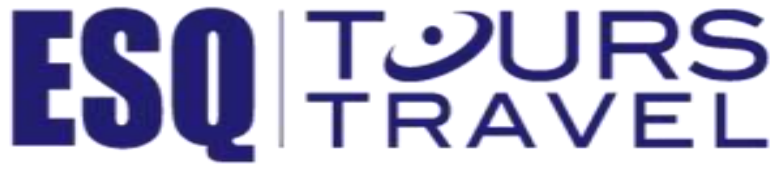

ESQ Tours \& Travel didukung oleh tenaga yang profesional dan mempunyai sertifikat dari ASITA (Association of The Indonesian Tours and Travel), IATA (International Air Transport Association), HIMPUH (Himpunan Penyelenggara Umrah dan Haji) , HPI (Himpunan Pariwisata Indonesia) berpengalaman di bidangnya.

\section{Unsur-unsur Utama Pemasaran pada Umroh ESQ Tours Travel}

Tabel 1, unsur-unsur utama pemasaran ESQ Tours Travel

\begin{tabular}{|c|c|c|}
\hline Segmentation & Targeting & Positioning \\
\hline $\begin{array}{c}\text { Secara segmen, } \\
\text { kantor pusat ESQ Tours }\end{array}$ & $\begin{array}{l}\text { Dalam hal pangsa } \\
\text { pasar yang menjadi }\end{array}$ & $\begin{array}{l}\text { Dilihat } \\
\text { posisioningnya, }\end{array}$ \\
\hline Travel di wilayah & sasaran target peserta & Tours Travel memiliki \\
\hline Ibukota Jakarta, di & umroh ESQ Tours & posisioning \\
\hline kawasan strategis untuk & Travel pada mulanya & berikut, "Togetherness in \\
\hline $\begin{array}{ll} & \text { Issnis dan } \\
\text { dengan } & \text { berbagas }\end{array}$ & $\begin{array}{l}\text { adalan mereka yang } \\
\text { berasal dari masyarakat }\end{array}$ & $\begin{array}{l}\text { Theaningrul Journey. } \\
\text { Tagline tersebut tidak }\end{array}$ \\
\hline perusahe & ekonomi menengah ke & hanya mengandung arti \\
\hline $\begin{array}{l}\text { luas dan mudah } \\
\text { dijangkau dari berbagai }\end{array}$ & $\begin{array}{l}\text { atas karena harga paket } \\
\text { umroh terendah }\end{array}$ & $\begin{array}{l}\text { bahwa dalam satu } \\
\text { pelayanan }\end{array}$ \\
\hline
\end{tabular}




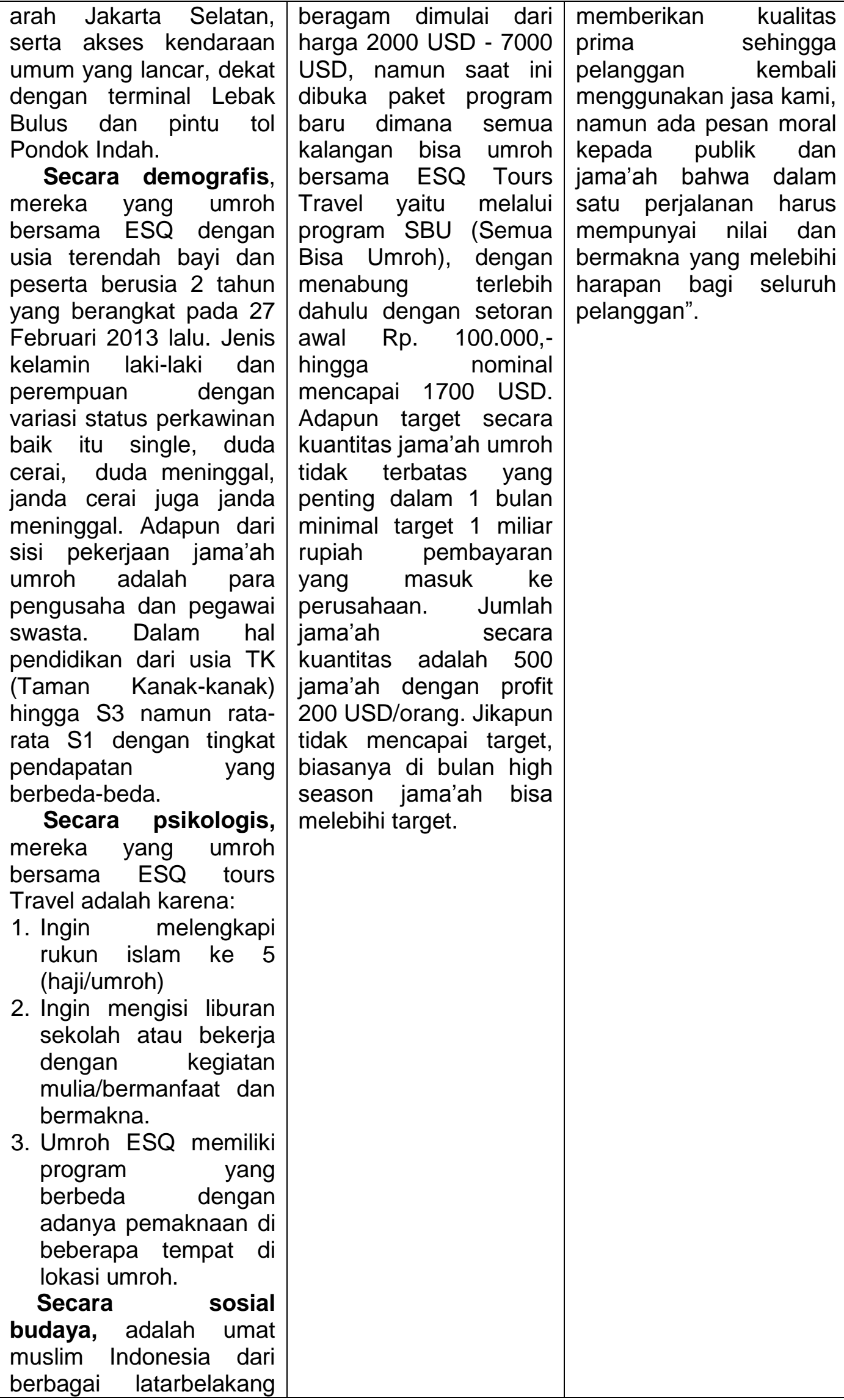




\begin{tabular}{|l|l|l|}
\hline suku dan budaya dan & & \\
dari kelas sosial & & \\
menengah ke atas. & & \\
Bahkan juga pernah ada & & \\
jama'ah dari manca & & \\
negara yaitu dari & & \\
Belanda, Australia dan & & \\
Jepang. & \\
\hline
\end{tabular}

\section{Analisi SWOT Produk Umroh ESQ Tours Travel}

Tabel 2, Analisis SWOT ESQ Tours Travel

\begin{tabular}{|c|c|}
\hline $\begin{array}{l}\text { 1. Strength } \\
\text { (Kekuatan) }\end{array}$ & $\begin{array}{l}\text { a. Popularitas dan pengaruh sosok Trainer kondang di } \\
\text { Indonesia dan luar negeri, Dr. H.C Ary Ginanjar } \\
\text { Agustian, } \\
\text { b. Kehandalan Dr. HC Ary Ginanjar Agustian } \\
\text { merepresentasikan jaminan kualitas program wisata } \\
\text { rohani umroh bersama ESQ Tours Travel. } \\
\text { c. Didukung oleh ESQ Leadship Center dalam hal } \\
\text { perekrutan/perolehan jama'ah umroh yang basis } \\
\text { terbesarnya adalah dari alumni ESQ Leadership Center. } \\
\text { d. Diback up kuat oleh } 12 \text { unit-unit bisnis lainnya dalam } \\
\text { ESQ Group, seperti ESQ Leadership Center. } \\
\text { e. Mendapat akses mudah dalam hal sosialisasi dan } \\
\text { publikasi iklan dan promosi ESQ Tours Travel oleh } \\
\text { media-media massa yang dimiliki ESQ Leadership } \\
\text { Center, } \\
\text { f. Program pemaknaan wisata rohani selama dalam } \\
\text { perjalanan dan di lokasi oleh para Trainer, Muthowwif, } \\
\text { dan Tour Leader. } \\
\text { g. Memiliki perusahaan penerbitan sendiri yang dimiliki } \\
\text { oleh ESQ Group sebagai salah satu unit bisnisnya, yaitu } \\
\text { Arga Tilanta. } \\
\text { h. Pelayanan dan fasilitas excellent selama perjalanan } \\
\text { umroh, } \\
\text { i. Lokasi kantor yang strategis di tengah-tengah kawasan } \\
\text { berkembang Jakarta Selatan, } \\
\text { j. SDM yang memiliki loyalitas dan integritas di bidangnya } \\
\text { masing-masing. } \\
\text { k. Kedekatan hubungan dengan Pemerintah terkait } \\
\text { I. Memilki kantor cabang di beberapa kota besar di } \\
\text { Indonesia. } \\
\text { m. Meraih berbagai macam penghargaan/Award, } \\
\text { n. Memiliki networking yang luas dengan berbagai } \\
\text { lembaga swasta/pemerintah di Indonesia. }\end{array}$ \\
\hline $\begin{array}{l}\text { 2. Weaknesses } \\
\text { (Kelemahan) }\end{array}$ & $\begin{array}{l}\text { a. Kurang simpel dalam proses administrasi berkas bagi } \\
\text { para calon jama'ah dan pencairan keuangan } \\
\text { operasional pegawai sehari-hari karena keuangan } \\
\text { terpusat. }\end{array}$ \\
\hline
\end{tabular}




\begin{tabular}{|c|c|}
\hline & $\begin{array}{l}\text { b. Harga pada setiap paket umroh di ESQ Tours Travel } \\
\text { tergolong mahal yang tidak bisa dijangkau oleh semua } \\
\text { kalangan dalam hal ini adalah kalangan menengah ke } \\
\text { bawah.). } \\
\text { c. Program pemaknaan umroh ESQ Tours Travel saat, bila } \\
\text { statis akan menjadi sebuah ancaman, karena jama'ah } \\
\text { akan bosan (boring). }\end{array}$ \\
\hline $\begin{array}{l}\text { 3. Opportunities } \\
\text { (Peluang) }\end{array}$ & $\begin{array}{l}\text { Berdasarkan berbagai macam kekuatannya, maka bisa } \\
\text { dijadikan sinyalemen bahwa ESQ Tours Travel memiliki } \\
\text { peluang yang besar dalam peta persaingan di industri jasa } \\
\text { wisata rohani, untuk terus memperluas jangkauan pasarnya } \\
\text { ke pasar Internasional, sebagaimana rencana manajemen } \\
\text { yang akan membuka kantor cabang di Malaysia pasca MEA } \\
\text { berlaku. }\end{array}$ \\
\hline $\begin{array}{l}\text { 4. Threats } \\
\text { (Ancaman) }\end{array}$ & $\begin{array}{l}\text { a. Kompetitor sesama perusahaan travel haji umroh yang } \\
\text { memiliki keunggulan juga khususnya mengenai fasilitas } \\
\text { dan pelayanan. } \\
\text { b. Inflasi yang terjadi saat ini di Indonesia. } \\
\text { c. Kondisi perekonomian yang turun saat ini } \\
\text { d. Rupiah yang terus melemah terhadap Dollar. }\end{array}$ \\
\hline
\end{tabular}

\section{Bauran Komunikasi Pemasaran Terpadu Umroh ESQ Tours Travel}

Membahas integrasi bauran strategi komunikasi pemasaran terpadu umroh ESQ Tours Travel berdasarkan model bauran IMC ke 3 dari teori George dan Michael Belch, sehingga didapat sebagaimana berikut:

Tabel 3, bauran pemasaran ESQ Tours Travel

\begin{tabular}{|c|c|}
\hline $\begin{array}{l}\text { Iklan } \\
\text { (advertising) }\end{array}$ & $\begin{array}{l}\text { a. Website, yang bisa diakses langsung ke } \\
\text { www.esqtours.com, atau ke www.esqgroup.co.id dan } \\
\text { www.esqnews.com serta www.esqway165.com } \\
\text { b. Email, dikirim ke seluruh alumni-alumni ESQ Leadership } \\
\text { Center, alumni haji dan umroh, alumni leisure termasuk } \\
\text { pencarian data calon jama'ah potensial berdasarkan } \\
\text { database ESQ Tours Travel. Dikirim melalui alamat email } \\
\text { cs@esqtours.com. infrormasi yang dikirimkan berupa } \\
\text { penawaran seputar umroh dengan mengirimkan } 160.000 \\
\text { email sebanyak } 2 \text { kali dalam seminggu. } \\
\text { c. Media massa, biasa digunakan untuk mengiklankan } \\
\text { umroh/haji adalah koran Jawa Pos dan Sindo juga } \\
\text { Republika yang rata-rata pemasangan iklannya } 2 \text { kali } \\
\text { dalam sebulan. Media massa ini dianggap dapat menyisir } \\
\text { sasaran lebih luas dan semua kalangan pembaca koran } \\
\text { tersebut karena berskala nasional } \\
\text { d. Baliho, dipasang di kantor pusat dan seluruh cabangnya, di } \\
\text { event-event pameran, dan di event-event ESQ Group. } \\
\text { e. Majalah, iklan dipasang di majalah ESQ Life dengan sistem } \\
\text { barter yaitu } 1 \text { kali pemasangan iklan umroh maka membeli }\end{array}$ \\
\hline
\end{tabular}




\begin{tabular}{|c|c|}
\hline & $\begin{array}{l}1000 \text { eksemplar majalah tersebut. } \\
\text { f. Flyer, berupa brosur, leaflet dan tabloid ESQ Tours yang } \\
\text { membuat infromasi/iklan ESQ lalu penyebarannya adalah } \\
\text { di seluruh kantor cabang dan pusat juga di kantor-kantor } \\
\text { seluruh unit bisnis ESQ Group. } \\
\text { g. Social media, mulai dari facebook dengan nama akun } \\
\text { ESQTOUR, twitter dengan nama akun esqtourstravel, bbm, } \\
\text { WA, dan Instagram yang bisa merambah kalangan netizen } \\
\text { yang potensinya lumayan besar di era digital saat ini. }\end{array}$ \\
\hline $\begin{array}{l}\text { Pemasaran } \\
\text { Langsung } \\
\text { (Direct } \\
\text { Marketing) }\end{array}$ & $\begin{array}{l}\text { Merupakan upaya perusahaan atau organisasi untuk } \\
\text { berkomunikasi secara langsung dengan calon pelanggan } \\
\text { sasaran dengan maksud untuk menimbulkan tanggapan dan } \\
\text { transaksi penjualan komunikasi langsung melalui berbagai } \\
\text { media, seperti telemarketing oleh call center, email, bbm, WA, } \\
\text { fb, twitter. }\end{array}$ \\
\hline $\begin{array}{l}\text { Pemasaran } \\
\text { Interaktif } \\
\text { (Internet } \\
\text { Marketing) }\end{array}$ & $\begin{array}{l}\text { Pemasaran interaktif yang dilakukan ESQ Tours Travel ini } \\
\text { adalah gabungan dari pemasaran langsung, periklanan dan } \\
\text { public relations, ditangani khusus oleh pegawai yang } \\
\text { menguasai ICT (Information and Communication Technology) } \\
\text { dengan memaksimalkan keberadaan serta fungsi aplikasi- } \\
\text { aplikasi berita, email, website, sosial media (FB, WA, BBM, IG, } \\
\text { Twitter) sehingga semakin memudahkan interaksi antara } \\
\text { pelanggan dengan marketing. }\end{array}$ \\
\hline $\begin{array}{l}\text { Promosi } \\
\text { Penjualan } \\
\text { (Sales } \\
\text { Promotion). }\end{array}$ & $\begin{array}{l}\text { Serangkaian promosi penjualan dilakukan oleh tim marketing } \\
\text { ESQ Tours Travel, tujuannya tidak lain adalah untuk } \\
\text { memperkenalkan produk-produk umroh ESQ Tours Travel } \\
\text { terbaru, atau untuk menyikapi penjualan yang sedang lesu, } \\
\text { atau untuk mengukuhkan brand atau juga untuk sebuah } \\
\text { eksistensi ESQ Tours Travel itu sendiri. Ada } 2 \text { macam promosi } \\
\text { yang biasa dilakukan berkaitan dengan produk jasa umrohny, } \\
\text { yaitu: Potongan harga umroh dan Exhibition/Expo/pameran } \\
\text { dagang tahunan seperti di GATF } 2015 \text { dan IIE } 2014 \text {. }\end{array}$ \\
\hline $\begin{array}{l}\text { Hubungan } \\
\text { Masyarakat } \\
\text { (Public } \\
\text { Relations) }\end{array}$ & $\begin{array}{l}\text { ESQ Tours Travel selama ini belum memiliki } \\
\text { divisi/bagian ke-PRan/kehumasan secara tersendiri, } \\
\text { meskipun membangun good relationship dan komunikasi } \\
\text { dua arah, pembangunan dan pengelolaan citra serta } \\
\text { publikasi, tetapi dilakukan oleh marketing komunikasi ESQ } \\
\text { Group selama ini. Namun bukan berarti dalam ESQ Tours } \\
\text { Travel tidak ada sama sekali usaha-usaha sebagaimana } \\
\text { disebutkan di atas, beberapa fakta berikut menjelaskan } \\
\text { bahwa ESQ Tours Travel pun menjalankan hanya saja } \\
\text { belum melembaga dan dikelola dengan baik bahkan terjadi } \\
\text { tumpang tindih bidang pekerjaan (multi job) oleh divisi lain, } \\
\text { yaitu: } \\
\text { a. Fungsi kehumasan/ke-PRan ada yang dilakukan } \\
\text { langsung oleh marketing ESQ Tours Travel, yaitu TCR } \\
\text { (Travel Consultant Retail) dan TCR, juga General }\end{array}$ \\
\hline
\end{tabular}




\begin{tabular}{|c|c|}
\hline & 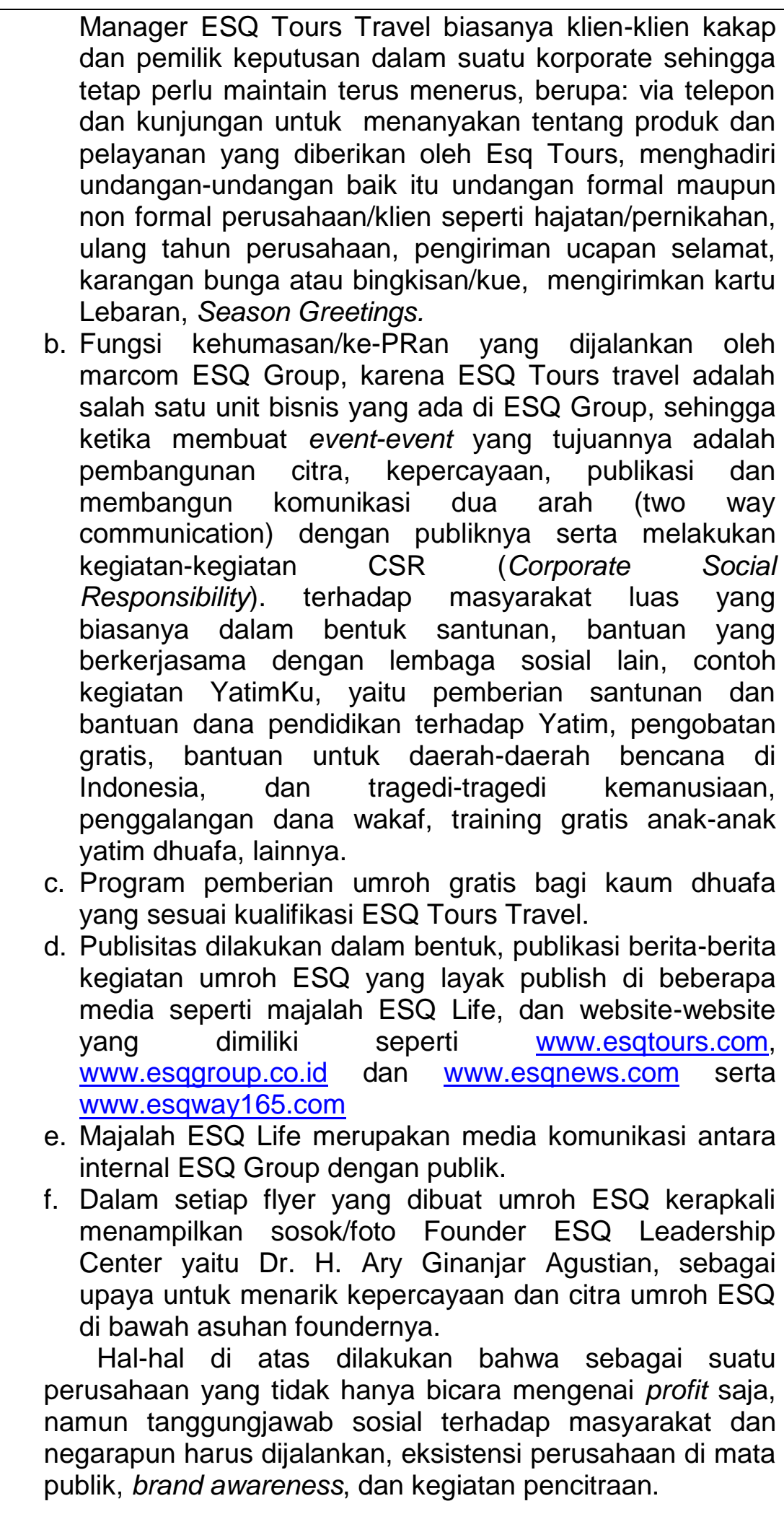 \\
\hline $\begin{array}{l}\text { Penjualan } \\
\text { Personal } \\
\text { (Personal } \\
\text { Selling) }\end{array}$ & $\begin{array}{l}\text { Ada } 3 \text { bentuk personal selling yang dilakukan umroh ESQ } \\
\text { selama ini, yaitu: } \\
\text { a. Retail Selling, yaitu melayani konsumen yang datang ke } \\
\text { kantor yang di lakukan oleh } 2 \text { bagian dalam marketing yaitu }\end{array}$ \\
\hline
\end{tabular}




\begin{tabular}{|l|l|}
\hline TCR dan CC. \\
bield Selling, yaitu tim marketing umroh ESQ mendatangi \\
konsumen/calon jama'ah/klien ke perusahaan/kantor- \\
kantor mereka yang dilakukan oleh TCC. \\
c. Executive Selling, yaitu approaching yang dilakukan oleh \\
$\begin{array}{l}\text { General Manager (GM) ESQ Tours Travel terhadap klien } \\
\text { kakap/elite. }\end{array}$
\end{tabular}

\section{G. Kesimpulan}

Berdasarkan hasil analisa dan pembahasan yang telah diuraikan pada bab sebelumnya, maka dapat ditarik kesimpulan sebagai berikut:

1. Dalam konteks aktivitas komunikasi pemasaran terpadu, ESQ Tours Travel memiliki keunikan tersendiri dan telah mampu mengintegrasikan dengan baik bauran komunikasi pemasaran terpadu yang dimiliki sebagai alat dalam memenangkan persaingan terhadap kompetitor-kompetitornya, antara lain: (1) advertising, (2) direct marketing, (3) intenet marketing, (4) promotion, (5) pulic relations, (6) personal selling.

2. ESQ Tours Travel dalam beriklankan ditangani langsung oleh bagian advertising dan promosi ESQ Group melalui berbagai media massa cetak nasional. ESQ Tours Travel pun telah mampu memaksimalkan keberadaan periklanan digital yaitu email, website serta berbagai sosial media untuk menyisir kalangan netizen, baik itu melalui WA, BBM, IG, WA dan Twitter. Iklan berupa flyer dan baliho, selain tersedia di kantor pelayanan dan kantor cabang, juga tersedia di kantor-kantor unit bisnis ESQ lainnya, serta event-event ESQ.

3. Komunikasi pemasaran dilakukan oleh divisi marketing khususnya oleh TCR dibantu oleh flyer yang sudah tercetak baik brosur, leaflet dan tabloid. Juga telemarketing/telesales oleh call center dan TCC khusus ditujukan bagi komunikasi pemasaran langsung dengan perusahaan-perusahaan, lembaga, organisasi dan instansi-instansi.

4. Kecanggihan teknologi informasi dan komunikasi saat ini menjadi alat pisau tajam bagi kegiatan komunikasi pemasaran interaktif umroh ESQ Tours Travel dalam memasarkan produk umroh ESQ yaitu menggunakan aplikasi-aplikasi berita yang bisa diunduh di play store dan google play, email, website, sosial media.

5. Promosi penjualan yang selama ini dilakukan oleh ESQ Tours Travel terhadap umroh ESQ dilakukan dengan cara, yaitu pemberian potongan harga (diskon) terhadap jama'ah pegawai ESQ dan keluarga pegawai serta alumni ESQ Tours Travel atau alumni training.

6. Kegiatan ke PR-an banyak dilkukan dalam rangka menjalin good relationship, kepercayaaan, saling pengertian, membangun dan menjaga citra, CSR, dan tanggungjawab sosial ESQ Tours Travel terhadap masyarakat luas. Dan dalam praktek pelaksanaanya dilakukan oleh TCR, TCC, juga MarCom ESQ Group, seperti penggalangaan dana YatimKU, bakti sosial pengobatan gratis, tragedi kemanusiaan, penggalangan dana wakaf, dan umroh gratis dengan kualifikasi dan rekomendasi khusus internal manajemen.

7. Dalam hal penjualan personal, ada tiga bentuk penjualan yang dilakukan selama ini yaitu retail selling, field selling, dan executive selling.

8. Didukung oleh networking yang kuat antar sesama unit-unit bisnis ESQ Group yang terintegrasi satu sama lain. 


\section{H. Saran}

1. Periklanan harus berani beriklan di media massa elektronik seperti Televisi, baik secara komersil maupun sebagai sponsor acara umroh gratis bagi masyarakat pengabdi umat yang berhak ke tanah suci dari satu sisi, namun memiliki keterbatasan finansial, atau bisa saja mensponsori dalam acara-acara "hijab hunt" atau "muslimah award" atau lainnya yang saat ini banyak dilakukan oleh media massa TV.

2. Dalam hal promosi, sesekali perlu melakukan strategi promosi lain, contohnya dengan mengadakan kontes ikhwan-akhwat/muslim-muslimah berprestasi atau yatim berprestasi dengan pemberangkatan umroh gratis bagi pemenang.

3. Dalam hal kehumasan/kePRan, alangkah lebih efektif jika secara khusus ESQ Tours Travel memiliki divisi/bagian atau staff khusus yang membidangi secara profesional di bidang PR perusahaan, mengingat selama ini terjadi tumpang tindih job.

\section{DAFTAR PUSTAKA}

Effendy, Uchjana Onong, (2002). Hubungan Masyarakat Suatu Studi Komunikologis, Remaja Rosda Karya, Bandung.

Morissan, (2010. Periklanan Komunikasi Pemasaran Terpadu, Kencana Prenada media Group, Jakarta.

Nazir, Moh, (1988). Metode Penelitia, Ghalia Indonesia, Jakarta.

Purwanto, Djoko, (2011). Komunikasi Bisnis, Erlangga, Jakarta. .

Rangkuti, Freddy, (2004). Analisis SWOT Teknik Membedah Kasus Bisnis Reorientasi Konsep Perencanaan Strategis untuk Menghadapi Abad 21, PT. Gramedia Pustaka Utama, Jakarta.

Ruslan, Rosady, (2003), Metode Penelitian PR dan Komunikasi, PT. Raja Grafindo Persada, Jakarta.

Setiawan, Michael dan Sutojo, Siswanto, (2003). Komunikasi Bisnis Yang Efektif, Damar Mulia Pustaka, Jakarta.

Soefijanto, Totok Amin dan Idris, Karlina lka, (2012). Integrated Marketing Communication, Komunikasi Pemasaran di Indonesia, Gramedia Pustaka Utama, Jakarta.

Soemanegara, Rd, (2006), Strategi Marketing Communication, Konsep, Strategi danTerapan, Alfabeta CV, Bandung. 